\title{
Pautas para cuidadores ${ }^{1}$
}

Suzanna Smith and Jennifer E. Gove ${ }^{2}$

¿Es usted un cuidador de un miembro frágil en la familia que necesita un poco de ayuda con sus actividades diarias? Algunas veces los cuidadores:

- Se sienten agobiados por las demandas de cuidar;

- Se les hace difícil compartir con familiares y amigos;

- No tienen tiempo para hacer ejercicio u otras actividades de preferencia; o

- Se sienten enfadados, tristes y solos algunas veces.

Si esto le suena familiar, usted como cuidador puede estar experimentando sobrecarga y estrés. Esta publicación le provee pautas para manejar el estrés, mantenerse saludable y le provee la ayuda necesaria para disfrutar la vida.

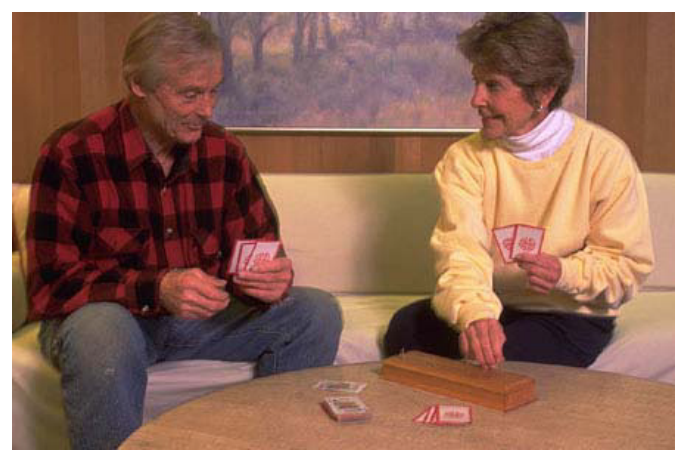

\section{Cargas y estrés del cuidador}

Los cuidadores expuestos a las muchas demandas del cuidado, normalmente experimentan sobrecarga. Esto significa que el cuidador empieza a sentir que el cuidar de otros empieza a traer impactos negativos para sus estados emocionales, salud física o estatus económico. Por ejemplo, algunos cuidadores se dan cuenta que estas demandas de cuidado disminuyen el tiempo y la energía para realizar actividades personales y relaciones con amigos. Los cuidadores pueden también dejar sus labores de cuidado a un familiar. Les puede preocupar que de pronto no les alcance el dinero para sus gastos del hogar debido al costo del cuidado médico. Estos cambios en la vida del cuidador pueden durar hasta que la ayuda para él sea necesaria.

A diferencia de sobrecarga, estrés se refiere al individuo sintiéndose presionado, fatigado, y deprimido. El estrés es la respuesta emocional a corto plazo para situaciones de cuidado a otros. Por ejemplo, un cuidador podría experimentar estrés si tuviese que cancelar una salida con amigos porque la persona que cuida se siente desorientada o deprimida. La sobrecarga, se refiere al impacto a largo plazo producido por esta situación en la vida del cuidador. El cuidador sobrecargado podría pensar "Por cuidar a Sam, ya no tengo una vida social."

1 The English version of this document is FCS2083. Este documento FCS2083-Spn, es uno de una serie del Departamento de Ciencias de la Familia, la Juventud y la Comunidad, Servicio de Extensión Cooperativa de la Florida, Instituto de Alimentos y Ciencias Agrícolas, Universidad de la Florida. Traducido por Rafael Arango y Claudia Peñuela: octubre de 2009. Por favor visite el sitio en la Web en EDIS http://edis.ifas.ufl.edu.

2. Suzanna Smith, Profesora Asociada, Desarrollo Humano y Jennifer E. Gove-Cooper, M.S., Coordinadora, Programa Académicos del Departamento de Ciencias de la Familia, la Juventud y la Comunidad, Servicio de Extensión Cooperativa de la Florida, Instituto de Alimentos y Ciencias Agrícolas, Universidad de la Florida, Gainesville, Florida 32611-0310 
A pesar de las dificultades de proveer cuidado, hay ciertos pasos que el cuidador podría tomar para reducir el estrés y para enfrentarse con la sobrecarga. Estos pasos incluyen el manejo del estrés, mantenerse saludable y lograrlo. Estos pasos le ayudarán al cuidador a reducir las demandas de cuidado para así disfrutar la vida en todos los aspectos.

\section{Manejar el estrés}

\section{Aceptar sus sentimientos}

Cuidar de otros es un trabajo difícil. Los cuidadores sienten un profundo sentido de cuidado, amor y orgullo. Ellos también pueden sentir rabia de la gran cantidad de demanda que hay hacia su tiempo. Se sienten apenados de que el anciano ya no es el mismo de antes. Se sienten sobrecargados por presiones financieras. Los cuidadores también pueden sentir que todas las cosas que ellos hacen no son valoradas. Todos estos sentimientos son normales. Sentimientos de rabia, frustración, impotencia no significan que usted como cuidador quiera menos a esta persona.

Reconocer y aceptar estos sentimientos es un paso necesario para resolver problemas, disminuir estrés y prevenir problemas físicos y emocionales.

\section{Entérese del estrés}

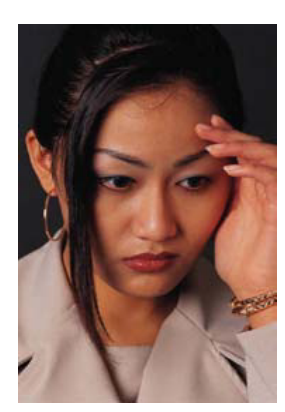

Los cuidadores esperan mucho de ellos mismos y se preocupan constantemente por no perjudicar a los demás. Puede que ellos no reconozcan sentimientos de estrés o sobrecarga en ellos mismos y a la larga terminan afectando su propia salud física y emocional.

El primer paso para combatir el estrés es darse cuenta que existe. Trate de monitorear su estrés con la siguiente lista de verificación de síntomas.

\section{Síntomas de estrés}

- Dolor de cabeza

- Fatiga

- Insomnio

- Cambio en su peso

- Molestias digestivas
- Incremento en el uso de alcohol, drogas, tabaco

- Cuello y hombros tensos

- Ansiedad

- Cambios de humor

- Llanto

- Irritabilidad

- Depresión

- Pérdida de memoria

- Poca concentración

- Baja productividad

- Actitud negativa

- Confusión

- Letargo

- Aburrimiento

- Sentimientos de aislamiento

- Hipertensión

Apenas empiece a sentir los síntomas del estrés, puede empezar a practicar ejercicios de relajación. Ponerse en posición cómoda - poner sus pies planos sobre el suelo, relajar los hombros y músculos faciales. Tomar respiración profunda hacia adentro, hacia fuera, hacia adentro, hacia fuera. $\mathrm{O}$, tómese unas vacaciones mentales. Póngase en posición cómoda, cierre los ojos, e imagínese en un lugar de su agrado, como en la playa o el atardecer.

\section{Actuar y pensar positivo}

Aquellos que mantienen una visión positiva de la vida, enfrentan mejor el estrés que aquellos que ven el mundo de manera negativa. Personas positivas "piensan" mejor las situaciones difíciles, cambiándolas de mal a bien. Personas positivas tienden a poner estas situaciones negativas a un período de largo plazo poniendo la situación en perspectiva. Los cuidadores tienden a sentirse menos estresados cuando afrontan los problemas de frente, se encargan de la situación y buscan soluciones. También, los cuidadores que sienten altos niveles de afecto por la persona que recibe el cuidado, se estresan menos. Los cuidadores deben poder mantener una perspectiva positiva al 
recordarse del amor y cariño que sienten por la persona que esta siendo beneficiada por ellos.

\section{Ejercite la mente positiva}

Empiece por relajarse y pensar de manera positiva. Usted mismo piense positivo:

"Realmente hice un buen trabajo cuidando de mi esposa hoy" o, "Salí a caminar para ejercitar y relajarme el día de hoy". Piense también positivo con pequeñas victorias con la persona de edad de su casa: "Parece sentirse mejor hoy y comió bien esta mañana".

Recuerde usted como se siente hacia la relación con la persona de edad: "Lo amo y hago todo esto para demostrarle que me importa". Reconozca las cosas buenas sobre otras partes importantes en su vida, como familiares o intereses personales. Por ejemplo, "A mi hijo Jim le fue bien en su examen de Algebra, estamos orgullosos de él". Y, "Anoche disfrute haber visto ese video con mi familia"

\section{Mantener la salud}

Una de las cosas más importantes que un cuidador debe hacer es cuidarse el mismo. Los cuidadores con buena salud tienden a sentirse menos sobrecargados. El cuidado personal apropiado también ayuda que los cuidadores prevengan problemas de salud, los cuales pueden interferir en el cuidado de la persona mayor y llevar a cabo la institucionalización de la persona que necesita de su ayuda. Buenas prácticas de salud permiten que el cuidador supla las demandas de cuidado y otras cosas que tengan que hacer. A continuación hay unas guías para mantener la salud.

\section{Comer comidas nutritivas}

La comida es el combustible de su cuerpo. Comer poco o saltarse comidas reduce la energía y lo pone en riesgos de tener problemas de salud. Aprenda a preparar y comer comidas simples y nutritivas.

\section{Hacer ejercicio y descansar}

La actividad física reduce el estrés y mejora la salud. Montar bicicleta, caminar, $o$ nadar es bueno y a la larga previenen varios problemas. Descansar es esencial para los cuidadores. Dormir con sonido es bueno para refrescar y habilitar al cuidador para que funcione mejor durante el día.

\section{Planear el tiempo de ocio}

El tiempo de ocio le ayuda a sentirse mejor y enfrentar las demandas del cuidado de otros, trabajar y tener una familia. Es muy importante sacar tiempo para hacer cosas que usted disfrute. Si usted es una mujer, usted debe tender a dejar de usar su tiempo libre para oportunidades de recreación y socialización. Si usted es un hombre, usted debe sacar tiempo para hacer actividades de su propio interés. Es muy importante tanto para los hombres como para las mujeres que estén protegidos contra el aislamiento y la depresión. Tengo tiempo solo pero también pase tiempo con los demás.

\section{Evite comportamientos destructivos}

Algunas personas manejan el estrés en formas destructivas para ellos y sus seres queridos. En vez de expresar los sentimientos, usan comida, drogas, o alcohol para esconder sus dificultades. Mientras construye su estilo de vida saludable, también cuídese de tener comportamientos destructivos. Si usa alcohol moderado, sea moderado. Use medicaciones cuidadosamente y solo como hayan sido prescritas. No coma de más. Si trata de hacer cambio es su estilo de vida, no lo tiene que hacer solo. Amigos, consejeros, familiares, cleros y grupos de cuidado le pueden ayudar.

\section{Buscar ayuda}

\section{Consiga ayuda de familiares y amigos}

Nuestra cultura se enfatiza en independencia, así que no es fácil pedir ayuda. La verdad es que cuidadores que reciben ayuda y apoyo de familiares y amigos tienden a sentirse menos estresados y tienden a cuidar mejor de esas personas que los necesitan. Cuidadores que reciben ayuda de los demás tienden a sentirse queridos. También pueden obtener ayuda práctica para cuidar, y trabajos en el hogar. Como resultado, los cuidadores tienden a solucionar problemas más fácilmente y prevenir que situaciones difíciles se empeoren. Su propia salud es más importante. 
Algunos familiares y amigos están dispuestos a ayudar pero no saben como preguntar. Ellos deben de mirarlo a usted, el cuidador, para una guía. Usted debe hacerles una sugerencia específica, como “¿Puedes visitar a mi madre por más o menos una hora mientras voy al mercado?" Déjele saber a la gente lo mucho que significa para usted la ayuda que ellos le puedan ofrecer.

Por otro lado, hay veces que los mismos familiares son críticos de sus cuidados. Así usted se enoje y se quiera rendir, trate de escuchar sus puntos de vista. Después, háblele de sus ideas y sus sentimientos. Trate de expresar sus sentimientos honestamente pero sin enemistad. Planee reuniones familiares de vez en cuando para así informar a los otros familiares de la situación o involucrarlos en el cuidado de la persona que lo necesita.

Nosotros pensamos que la ayuda que podamos recibir solo viene de familiares y amigos, pero aquellos cuidadores que sienten ayuda espiritual también se sienten menos estresados. Cultive sus creencias espirituales en la manera que sea significativa para usted - orar o meditar, ir a misas, o caminar por bosques y observar el atardecer.

\section{Obtenga la ayuda que necesita}

Hay recursos comunitarios disponibles que le pueden ayudar a proveer cuidado a su ser querido y para reabastecer su propia vitalidad. Hay veces es difícil ir a buscar ayuda comunitaria. Pero no es nada inusual que un cuidador busque ayuda para cuidar.

\section{Únase a un grupo de ayuda}

La mayoría de las personas se sienten beneficiados al compartir sus sentimientos con alguien que los escucha y no los juzga. Grupos de apoyo pueden ayudar a los cuidadores a no estar tan solos y a construir buenas amistades. Estos grupos también pueden informarlo de cómo mejorar sus habilidades de cuidado.

\section{Use los recursos comunitarios}

Muchos de los cuidadores reportan que no usan recursos comunitarios porque no los necesitan. Sin embargo, profesionales que trabajan con familias de cuidadores dicen que los cuidadores tienden a no sentirse como que ellos necesitan ayuda hasta que llegan a una crisis o al punto que ya no pueden continuar. Se les aconseja a los cuidadores que busquen ayuda antes de llegar a una crisis. Hay muchos recursos comunitarios que están disponibles para ayudar a personas mayores y a sus familias. Así los servicios dependan de las comunidades, algunos de los servicios más comunes estas listadas a continuación. Para mayor información sobre que puede encontrar en su comunidad, contacte su Agencia más cercana. En Florida, el número para llamar es 1-800-262-2243. Su librería local también puede ofrecerle recursos, libros y referencia del envejecimiento, cuidado e información sobre asilos para personas mayores.

\section{Guía para recursos comunitarios}

- Alertas médicas en el hogar. Un aparato electrónico que se encarga de mandar señal a un lugar central donde informa si la persona se ha caído o necesita ayuda.

- Servicios para ayuda del hogar. Ayuda con las tareas del hogar y reparaciones menores para mantener a la persona viviendo independientemente.

- Cuidado de la salud en el hogar. Asistencia con medicaciones y la higiene personal como bañarse, usar el baño y comer.

- Servicios de nutrición. Comidas calientes llevadas a los domicilios de personas mayores y juntar comidas provistas en centros de adultos $\mathrm{u}$ otros centros comunitarios.

- Servicios de transporte. Camionetas o buses desde y hacia programas de congregación de comida, citas médicas, ir de compras, ir al banco y secciones de rehabilitación.

- Compañías y visitas amigables. Amistad, apoyo, compañía, o supervisión para los adultos por unas cuantas horas.

- Tranquilidad telefónica. Contactos regulares y amistosos a personas mayores 
que no puedan salir de su casa y estén enfermas.

- Cuidado auxiliar. Servicios ofrecidos para personas con un familiar enfermo o en rehabilitación. Este cuidado auxiliar libera al cuidador para hacer más cosas, como compras, preparación de las comidas, o tiempo de ocio y actividades sociales. La ayuda auxiliar puede ser conseguida con amigos, familiares, voluntarios o compañeros pagados o servicios profesionales en programas de cuidado diario, asilos y hospitales.

- Cuidados diarios para adultos. Cuidado supervisado y ofrecido para personas mayores con necesidades de cuidados de salud y estimulación social. Estos programas varían, pero pueden incluir monitoreo médico, comidas y actividades recreativas. El cuidado diario para adultos permite a algunos cuidadores continuar con un empleo y al mismo tiempo preocuparse por su ser queridos o tener tiempo extra para otras actividades.

- Manejo y planeamiento del cuidado. Ayuda profesional para escoger los mejores arreglos y en seguir el progreso.

\section{Referencias}

Administration on Aging. (2000). Elder action: Action ideas for older persons and their families. Retrieved July 16, 2003 from http://www.Aoa.dhhs.gov/aoa/eldractn.car egive.html.

Allen, K. R., Blieszner, \& Roberto, K. A. (2000). Families in the middle and later years: A review and critique of research in the 1990s. Journal of Marriage and the Family, 62, 911926.

American Association of Retired Persons. (n.d.) Balancing work and caregiving. Retrieved July 16, 2003, from http://www.aarp.org/confacts/caregive/bal ance.html.
Begany, T. (1996). Caring for the caregiver. Patient Care. 30, 108-132.

Bensing, K.M.. (2002). Helping hands: Caregiving resources. Library Journal. 127, 65-68.

Braus, P. (1998). When the helpers need a hand. American Demographics. 20, 6672.

Hooyman, N., Gonyea, J., \& Montgomery, R. (1985). The impact of in-home services termination on family caregivers. The Gerontologist, 25, 141-145.

Mastlish, R. (no date). Help for the working caregiver. Washington, DC: American Council on Life Insurance.

Montgomery, R. (in press). Gender differences in patterns of child-parent caregiving relationships. In J. Dwyer \& R. Coward, Gender, families, and elder care. Newbury Park, CA: Sage Publications.

National Council on the Aging (1988). Taking care of yourself while you take care of others. Washington, DC: The National Council on the Aging.

National Council on the Aging (1988). Respite: You deserve a break. Washington, DC: The National Council on the Aging.

Osterkamp, L. (1988). Family caregivers: America's primary long-term care resource. Aging, 358, 3-6.

Parent Care. (1989). National survey of caregivers finds low use of helping services. Parent Care, 4.

Parent Care (1985). When is caregiving more stressful? Parent Care, 1.

Schmall, V.L. \& Stiehl, R.E. (1987). Coping with caregiving: How to manage stress when caring for elderly relatives (PNW 315). Corvallis: Oregon State University.

Stoller, E. P. (1992). Gender differences in the experiences of caregiving spouses. In J. Dwyer \& R. Coward, Gender, families, and elder care. Newbury Park, CA: Sage Publications. 